\title{
China kickstarts its vaccine market
}

China recently introduced a major new commercialization policy that includes a budget to support research in the country's vaccine industry. Some say the policy, together with the earlier dissolution of the state monopoly on purchasing vaccines, will make the biotech sector in China more competitive and allow entry of foreign vaccine developers. Others believe it can put new vaccines onto the Chinese market if vaccine companies invest in research and introduce marketing strategies that raise awareness among the general population of the need for vaccines.

China's powerful National Development and Reform Commission (NDRC) announced in January that it will allocate an undisclosed amount of funding to support new vaccine development in the country. That measure comes on the heels of a new rule introduced in June 2005, where the Chinese cabinet deregulated the vaccine sector, thus breaking the monopoly of the State-controlled Chinese Center for Disease Control (CDC) to purchase vaccines. The new measure allows local hospitals and desease control departments to buy commercial vaccines directly from producers for the first time.

"Besides the funding, the significance of the new policies lies in the fact that they eliminate the privileges enjoyed by stateowned enterprises by stipulating that all

"The [new] policy is to take vaccine as a breakthrough point to promote the innovation of the whole biotech sector," says Jingyu Bai, biotech section chief at the National Development and Reform Commission.

developers can apply for the money and market their products to end-users directly," says Yongqing Cheng, president of Beijingbased vaccine company Triprime Biotech. "This would be a big bonus to our private research-based biotech firms."

"The [NDRC] policy is to take vaccine as a breakthrough point to promote the innovation of the whole biotech sector," says Jingyu Bai, biotech section chief of NDRC. He adds that his commission will organize third-party evaluations to decide which vaccine developers are eligible for the government funding. Triprime Biotech's president Cheng, who has participated in the discussion on the policy, says that for each eligible vaccine developer, at least several million Yuans (8 Yuans equal $\$ 1$ ) of funding will be available. "If we could obtain the financial support from NDRC, it will be easier for us to speed up the clinical trial process," comments Zixin Qiu, president of Beijing-based Wantai Biopharmaceutical. "The overall strength of our company will be improved."

China's vaccine research base has developed significantly in recent years. In November 2003, Beijing-based, AMEX-listed Sinovac Biotech developed the first vaccine for severe acute respiratory syndrome (SARS). And in November 2005, China's State Food and Drug Administration gave the green light for Sinovac to launch the clinical trial for a human H5N1 avian flu vaccine. Last December, Wantai Biopharmaceutical completed phase 2 testing of a new vaccine against hepatitis $\mathrm{E}$ virus.

Weidong Yin, president of Sinovac, estimates that the sales volume of China's commercial vaccines reached RMB 3 billion ( $\$ 372.7$ million) in 2004 and has kept an annual growth rate of $15 \%$ since 2001. And the market does not belong to Chinese biotech firms alone. According to Yin, major foreign developers, such as London-based GlaxoSmithKline (GSK), Sanofi Pasteur, the vaccine subsidiary of Sanofi Aventis located in Lyons, France, and Chiron, now part of Novartis, Basel, have already conquered about half of the Chinese commercial vaccine market.

Despite the huge market potential and the favorable policies, barriers remain for both Chinese biotech firms and international vaccine developers. Compared with the vaccine landscape of mature markets, there are still too many vaccine producers in China; there are about 28 major vaccine developers in the country according to Yin's estimates. But few of them have a sales volume of more than RMB 100 (\$12) million. The cutthroat competition has therefore severely thinned their profits. Yongqiang $\mathrm{Wu}$, an executive of the strategy planning department at the stateowned vaccine company China National Biotech, says the low profit margin has made it very diffictult for the largest biotech firm

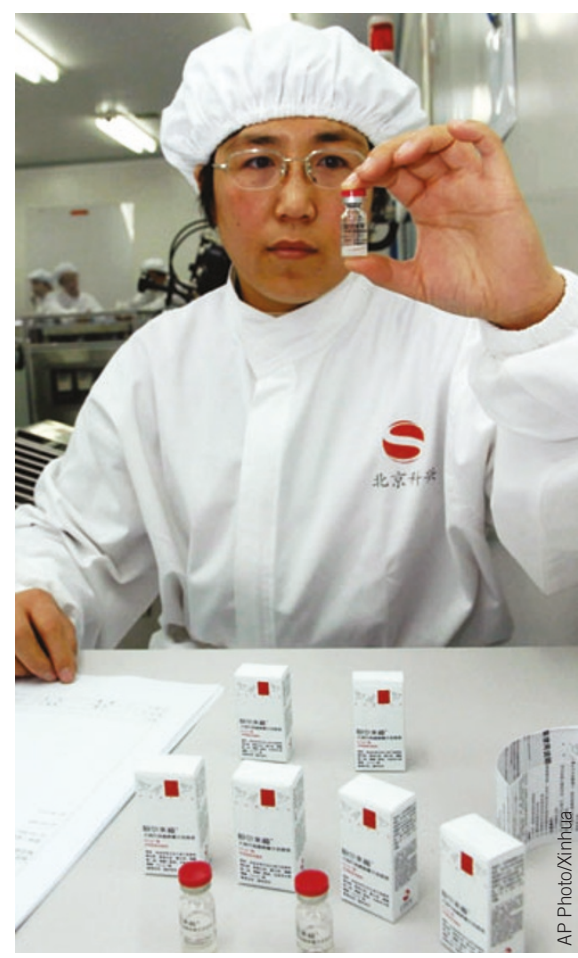

The Ministry of Science and Technology of China announced last November that Chinese scientists had developed human vaccines for bird flu (pictured here). The new budget allocated to vaccine development will help further research for this type of vaccine.

in China to reinvest money in research and to improve vaccine production techniquesunlike their foreign competitors.

But the main hurdle remains that biotech companies in China do not have much experience with marketing, which puts them at a disadvantage compared to foreign competitors. "In the past, the provincial branches of CDC helped us a lot in increasing people's awareness of vaccination, but now, with deregulation, we will have to hold public education step by step," says Qing Yi, a spokeswoman for Sanofi Pasteur's Beijing branch. In China, people are poorly informed about vaccinations. Most adults, for example, think they received all the necessary vaccinations before they were two years old. Therefore, a vaccine marketing strategy has to be focused not only on how good a product is, but also on why it is necessary for an individual to get vaccinated. For businesses to do this on their own is an enormous task, if not a burden.

Hepeng Jia, Beijing 